\title{
Changes and controlling factors of cropland soil organic carbon in North China Plain over a 30-year period
}

\author{
Daorui Han • Zhigang Sun • Fadong Li • \\ Ruixing Hou • Jing Li • Zhu Ouyang • Binbin Li • \\ Changwei Cao
}

Received: 11 August 2015 / Accepted: 11 January 2016 / Published online: 6 February 2016

(C) Springer International Publishing Switzerland 2016

\begin{abstract}
Aims Try to detect the spatiotemporal dynamics and the controlling factors of soil organic carbon (SOC) in the North China Plain (NCP) over the last 30 years: 1980s-2010s.

Methods We investigated the SOC evolution by compiling data from 32 published papers during the last 30 years. Then we examined the spatial pattern and controlling factors by analysing a two-period sampling observations (1980s and 2010s) and multiple explanatory variables in four typical counties.
\end{abstract}

Responsible Editor: Ingrid Koegel-Knabner.

Electronic supplementary material The online version of this article (doi:10.1007/s11104-016-2803-7) contains supplementary material, which is available to authorized users.

D. Han · Z. Sun $\cdot$ F. Li · R. Hou · J. Li $\cdot$ Z. Ouyang $\cdot$ B. Li Key Laboratory of Ecosystem Network Observation and Modeling, Institute of Geographic Sciences and Natural Resources Research, Chinese Academy of Sciences, Beijing 100101, China

D. Han $\cdot$ Z. Sun $\cdot$ F. Li $\cdot$ R. Hou $\cdot$ J. Li $\cdot$ Z. Ouyang $(\bowtie) \cdot$

B. $\mathrm{Li}$

Yucheng Comprehensive Experimental Station, China Academy of Science, Beijing 100101, China

e-mail: ouyz@igsnrr.ac.cn

D. Han

University of Chinese Academy of Science, Beijing 100049,

China

C. Cao

Bureau of Agriculture and Animal Husbandry, Luancheng

CountyShijiazhuang 050000, China
Results Over the last 30 years, the agronomy environment and management practice have been dramatically improved, which have largely increased the crop yield and subsequently enhanced the $\mathrm{C}$ input into the soil, made NCP the most effective region for $\mathrm{C}$ sequestration in China, ranging from $5.55 \pm 1.28 \mathrm{~g} \mathrm{~kg}^{-1}$ in the $1980 \mathrm{~s}$ to $8.71 \pm 1.22 \mathrm{~g} \mathrm{~kg}^{-1}$ in the $2010 \mathrm{~s}$, with an average rate of $0.11 \mathrm{~g} \mathrm{~kg}^{-1}$ year $^{-1}$. The SOC change (SOCC) exhibited spatial heterogeneity due to imbalanced agricultural management (i.e., rotation and irrigation) and environmental obstacles (i.e., salinity and water deficit). The mean SOCC rate in Fengqiu and Yucheng (> $+0.15 \mathrm{~g} \mathrm{~kg}^{-1}$ year ${ }^{-1}$, with rotation of winter wheat and summer maize, less water deficit and salinity stress) were significantly $(P<0.05)$ higher than that in Nanpi $\left(<+0.10 \mathrm{~g} \mathrm{~kg}^{-1}\right.$ year $^{-1}$, with water deficit $)$ and Kenli $\left(<+0.10 \mathrm{~g} \mathrm{~kg}^{-1}\right.$ year ${ }^{-1}$, cotton only, salinity stress). Conclusions SOC may continue to increase in the NCP through sustainable and efficient agricultural management, especially in low-yield region. Soils in the NCP will still act as a $\mathrm{C}$ sink well in the future.

Keywords Huang-Huai-Hai Plain · Soil organic carbon change - Spatiotemporal pattern $\cdot \mathrm{C}$ input .

Recommended management practices
Abbreviations
SOC soil organic carbon
NCP North China Plain
NPP net primary production
TWI topographic wetness index
TOP topographic parameters 
ASL above sea level

RMPs recommended management practices

MAT mean annual temperature

MAP mean annual precipitation.

\section{Introduction}

Soil is estimated as the largest organic $\mathrm{C}$ reservoir in terrestrial ecosystems considering its huge soil organic carbon (SOC) content (approximately 1550 $\mathrm{Pg}$ ), which is two times the size of the atmospheric pool and three times the size of the vegetation pool (Lal 2004a). Small changes in the soil pool can lead to large variations in atmospheric $\mathrm{CO}_{2}$ concentrations and can potentially release $\mathrm{CO}_{2}$ to the atmosphere. Given the rising $\mathrm{CO}_{2}$ concentration in the atmosphere, more attention has been attached to soil carbon sequestration due to its role in greenhouse gas (GHG) emissions, as well as in sustaining productivity, in ecosystem services, and in the sustainability of the global earth system. Cropland occupies $38 \%$ of the earth's land surface (The World Bank 2012) and contains approximately $69-89 \mathrm{Pg}$ of SOC globally (Jobbagy and Jackson 2000; Lal 2004b). The great potential of agricultural soil carbon sequestration has been widely claimed by adapting the recommended management practices (RMPs) (Lal 2002, 2004a). The $\mathrm{C}$ restored in agricultural soils has been estimated to reach $0.4-0.8 / 0.9 \mathrm{Pg} \mathrm{yr}^{-1}$ in the next 50100 years (IPCC 1996; Paustian et al. 1998; Smith et al. 2007). The carbon storing capacity of agricultural soils is meaningful for reducing $\mathrm{CO}_{2}$ emissions on both a national and global scales (Hutchinson et al. 2007).

The soil carbon dynamics of cropland are determined by the balance of $\mathrm{C}$ inputs and outputs, which are both influenced by natural and anthropogenic environmental changes. Previous studies have proven that optimal agricultural management practices can significantly affect the SOC dynamics in multiple ways. For example, irrigation and fertilizer application can enhance the SOC content by improving the net primary production (NPP) of the crops. In addition, agricultural machinery (combine harvesters, rotary tiller and subsoiler, etc.) makes $\mathrm{C}$ transfer more efficiently to the soil by returning crop residues. However, the benefits of these agricultural practices are highly dependent on the climate and soil conditions for specific crop systems (Luo and Weng 2011; Smith et al. 1997). In the context of climate change and its effects on NPP and heterotrophic respiration, growing efforts have been made to investigate the response of crop productivity and SOC to climatic variables in croplands using different methods (monitoring data, yield data and modelling) (Lobell et al. 2008; Peng et al. 2004; Thomson et al. 2006), but the results of these studies remain inconclusive (Ciais et al. 2011). For instance, global warming with an abundance of precipitation would result in $\mathrm{C}$ sequestration through improved photosynthesis, but it could also stimulate microbial decomposition of SOM, and thus releasing additional $\mathrm{C}$ to the atmosphere (Muller and Hoper 2004; Vukicevic et al. 2001). Davidson and Janssens (2006) noted that the inherently diverse nature of SOM and environmental constraints obscured the responses of SOC dynamics to warmer temperatures. Regardless of the climate scenarios or the management practices, the initial $\mathrm{C}$ content in soils negatively affects their $\mathrm{C}$ accumulation (Goidts et al. 2009; Meersmans et al. 2011; Saby et al. 2008; Thomson et al. 2006; Zhao et al. 2013), because the rate and duration of $\mathrm{C}$ gain is determined by the difference between the initial $\mathrm{C}$ content and saturation level, called the saturation deficit (West and Post 2002; West and Six 2007).

Recent assessments of SOC changes on cropland of China using meta-analysis, $\mathrm{C}$ inventory data or modelling methods found that the SOC pool in croplands has increased by $0.26-0.47 \mathrm{Pg}$ from the 1980s to the 2000s (Huang and Sun 2006; Xie et al. 2007; Yu et al. 2009). They claimed the most important driving factors were the increasing $\mathrm{C}$ input through improved land management practices (i.e., wide application of nitrogen fertilizer, irrigation area expansion and increased mechanization) ( $\mathrm{Ju}$ et al. 2009; Liu et al. 2014; Lu et al. 2009) and climatic factors (i.e., temperature, precipitation, tropospheric $\mathrm{O}_{3}$, and $\mathrm{N}$ deposition) (Ren et al. 2012; Yu et al. 2009), while Yu et al. (2009) asserted that improved agricultural options are the major contributor.

The North China Plain (NCP) is the largest and most productive agricultural region in China, covering a total cropland area of $18 \mathrm{Mha}$, with a dominant crop system of continuous winter wheat-summer maize dual-crop rotations. More than half of the nation's wheat and one-third of its maize are supplied by this region (Kendy et al. 2003). Due to thousands of years of 
conventional cultivation and an adverse environment (e.g., floods, drought and salinity), one of the most significant characteristics of soils in the NCP is low organic C content (Thomson et al. 2006). It has been challenging to find efficient practices that increase the organic C in the soils of the NCP (Lu et al. 2014). A recent study found the largest SOC increase occurred in Fluvisols $(+30.5 \%)$ in China during the period from 1978 to 1982 to 2007-2008 (Yan et al. 2011), bur its controlling factors were still unclear. As the most widely distributed soil unit, the SOC dynamics of Fluvisols (FAO taxonomy; fluvo-aquic, Genetic Soil Classification of China) are essential for the sustainability of agricultural productivity and food security in China. Therefore, we employed data from multiple sources trying to address the following objectives: 1) to explore the spatial and temporal patterns of SOC changes over the past three decades; 2) to detect the driving or impeding factors that control the SOC sequestration; 3) to propose adaptive management practices to meet future food security and climatic challenges.

\section{Materials and methods}

Study area

North China Plain, also called Huang-Huai-Hai Plain, with an area of $3.5 \times 10^{5} \mathrm{~km}^{2}$, is formed by the deposits of the Yellow River and is the largest alluvial plain of eastern Asia. Our study area focused mainly on its northern part which divided by the Yellow River, including Hebei province, northwest part of Shandong province, Northern part of Henan province, Beijing and Tianjin city (Fig. 1). The mean annual precipitation (MAP) is $500-600 \mathrm{~mm}, 70-80 \%$ of which fall in the period from June to September (Fang et al. 2006; Liu et al. 2010) as influenced by the monsoon. The mean annual temperature (MAT) ranged from $2.0^{\circ} \mathrm{C}$ in northern Hebei to $14.3{ }^{\circ} \mathrm{C}$ in southern Henan (Chinese Meteorological Administration, CMA). The majority of this area is less than $50 \mathrm{~m}$ above sea level (ASL). Fluvisols (FAO taxonomy; fluvo-aquic; Genetic Soil Classification of China, GSCC) that developed in the alluvial and coastal plains are the dominant soil group in

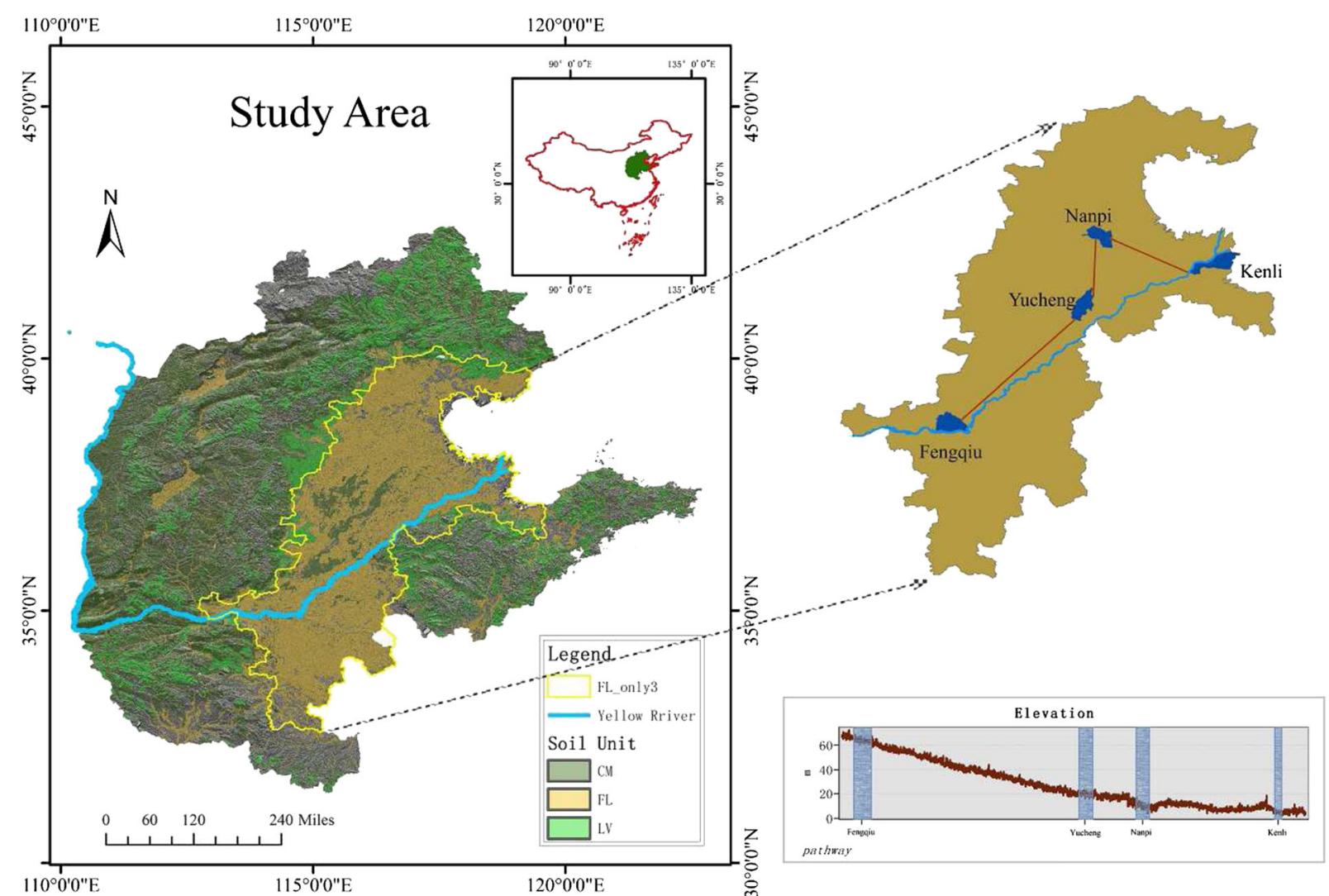

Fig. 1 Study area of Fluvisols in the North China Plain and four typical counties with their elevation 
the NCP. Four counties with high quality data records during the past 30 years were chosen along a roughly north to south transect. Fengqiu (FQ, $612.2 \mathrm{~mm}$, $\left.14.2{ }^{\circ} \mathrm{C}, 64.0 \mathrm{~m}\right)$ is situated in east Henan province, Yucheng (YC, $565.2 \mathrm{~mm}, 13.3{ }^{\circ} \mathrm{C}, 15.4 \mathrm{~m}$ ) and Kenli (KL, $541.7 \mathrm{~mm}, 13.1{ }^{\circ} \mathrm{C}, 5.1 \mathrm{~m}$ ) are in northwest Shandong province, and Nanpi (NP, $532.7 \mathrm{~mm}$, $12.8{ }^{\circ} \mathrm{C}, 9.6 \mathrm{~m}$ ) is in east Hebei province (Fig. 1). The SOC content dynamics of the croplands and their controlling factors in 0-20 cm depths were detected from the 1980 s to the 2010 s (Fig. 2).

\section{SOC data}

Data of SOC content $(0-20 \mathrm{~cm})$ in this study can be divided into two subsets. One was collected from published literature available at CNKI (http://www.cnki. net/). These papers were screened by the following criteria: 1) regional soil surveys or inventories (i.e., county scale or provincial scale) conducted in/ involving Fluvisols in the NCP from the 2nd NSS $(1980$ s) to 2012,2$)$ obtainable SOC, SOM content or SOC stock coupled with bulk density and depth, and 3) SOM measurements were consistent with that used in the 1980s. Following these criteria, more than 70,000 observations were compiled from a total of 32 publications. For the graphically illustrated data, figures were digitized using Engauge Digitizer software (Free Software Foundation, Inc., Boston, MA, USA). All data collected from papers was converted to SOC content for further statistical analysis. This data set was employed to detect the temporal evolution of SOC in the topsoil (0-
$20 \mathrm{~cm}$ ). We defined the SOC change (SOCC) as the difference between the initial and final values in the reported period. SOC changes often depend on the baseline SOC values, and the relative change in the baseline may better reflect the SOC change under climate change and land use management (Pan et al. 2010), Similar to Bellamy et al. (2005), we utilized the SOCC rate $\left(\mathrm{g} \mathrm{kg}^{-1}\right.$ year $\left.^{-1}\right)$ to trace SOC dynamics, which is calculated using the following equation:

SOCC rate $=\left(S O C_{t}-S O C_{0}\right) / t$

where $\mathrm{SOC}_{0}$ is the initial SOC content $\left(\mathrm{g} \mathrm{kg}^{-1}\right)$ at the beginning of the soil survey and $\mathrm{SOC}_{\mathrm{t}}$ is the final SOC content $t$ years after the initial soil survey.

The second subset consists of 807 soil profiles in four typical counties (Fig. 1). These data were analysed from two soil sampling campaigns conducted in the $1980 \mathrm{~s}$ (2nd NSS) and 2010s (2009-2010), of which 524 obervations were originated from the specific countyscaled soil monographs. These monographs contain detailed environmental descriptions of the soil profile, such as the location, vegetation type, land use, soil colour, SOM content, soil texture, soil water retention capacity, and some chemical properties (i.e., content of N-P-K, pH, EC) from 1979 to 1986 . All of the data were synthesized using hundreds of plot-specific measurements calculated according to their soil types or land use types on the basis of the soil-unit maps of each county with a scale of 1:50,000. The remaining 283 observations were derived from our regional cropland soil survey of northern China. We selected 14 typical
Fig. 2 Dynamics of the soil organic carbon (SOC) content from the 1980 s to the 2010 s for cropland across the North China Plain (NCP). Data were extracted from published literature on the same soil unit (references in Table S1)

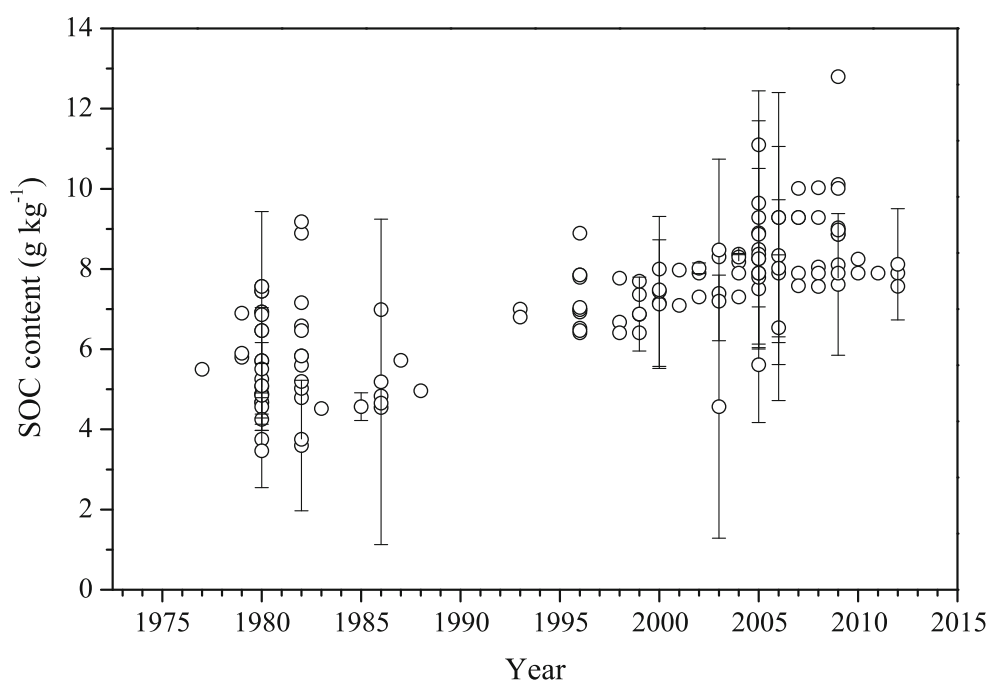


counties in northern China and conducted a soil resampling campaign during 2009 and 2010. In June and July before fertilization, we set evenly distributed 72 plots in each county, including 48 two-layer (0-20 cm and 20$40 \mathrm{~cm})$ plots and 24 soil profiles $($ depth $>=100 \mathrm{~cm}$ ) according to the soil categories, paedogenesis and land uses and considering the morphology, management practices and the amount of crop biomass, In each plot, three subplot samples of each layer were mixed for soil physical and chemical analysis in the laboratory. The soil samples were air-dried, sieved through a 2-mm mesh, and handpicked to remove plant detritus before analysis. The SOM was obtained by the wet oxidation method as described by Lu (1999), which is consistent with the measurement used in the 2nd NSS, a factor of 1.1 was used in order to correct for incomplete $\mathrm{C}$ oxidation. The SOC content was converted from the SOM using a Bemmelen index of 0.58. This SOC dataset was used to compare the 1980s and 2010s on the county and site levels. To make a site-to-site comparison, we matched the two-period sampling sites by Kriging interpolation. Specifically, considering the sampling density and soil heterogeneity of the two periods, we interpolated data from the 2 nd NSS of each county to generate a spatial distribution of the SOC content. We firstly used Kolmogorov-Smirnov Test to check the normality of our data. During spatial interpolation, a semivariogram was constructed to explore spatial dependence in the underlying variable (Cressie 2015).
Three types of semivariance models (i.e., Gaussian, Exponential, and Spherical) were tested to explore the relationship between the semivariance and the distance for SOC content in the 1980s. All semivariograms were optimized to obtain the best fitness between models and data. The final form of the theoretical variogram model was selected based on the results of a validation scheme (Cross-validation procedure). The prediction performance of Kriging was evaluated by comparing observed and estimated value. The exponential model was eventually adopted on the basis of the criteria that mean errors between the predicted and measured values was closest to zero, and our data in the 1980 s was interpolated to the $1 \mathrm{~km} \times 1 \mathrm{~km}$ grid for each county, we then calculated the SOC change by comparing the actual observations during the resampling campaign (2010s) with the extracted ones from the spatial interpolation of the 1980s.

\section{Explanatory variables}

Annual organic carbon (OC) input to soil: As the importance of OC input for the SOC accumulation, we calculated the annual total OC input from wheat and corn residues after harvest. According to the method of Johnson et al. (2006) and Bolinder et al. (2007), we divided NPP carbon content into three fractions $\left(\mathrm{g} \mathrm{m}^{-2}\right.$ years $\left.{ }^{-1}\right)$. The equations we used as follows:

$$
N P P_{C}=C_{G}+C_{S}+C_{R}, \quad \text { where } \begin{cases}C_{G}=Y_{P} \times 0.4 & (a) \\ C_{S}=\left(Y_{P} \times 0.4\right) / k_{1} & (b) \\ C_{R}=Y_{P} \times\left(1+k_{1}\right) /\left(k_{1} \times k_{2}\right) & (c)\end{cases}
$$

Where $N P P_{c}$ is the OC content from net primary productivity, $C_{G}, C_{s}$ and $C_{R}$ means OC from grain yield, straw and root with its rhizodeposit, respectively. The amount of $\mathrm{C}$ in each of these fractions can be estimated from agricultural grain yields, using published or assumed values for grain to straw ratios $\left(k_{l}=\right.$ grain/straw), and aboveground biomass to belowground biomass ratios $\left(k_{2}=\right.$ aboveground biomass $\mathrm{C} /$ belowground biomass $\mathrm{C}$, here belowground biomass $\mathrm{C}$ include root $\mathrm{C}$ and rhizodeposit $\mathrm{C}$ ), and $\mathrm{C}$ concentrations in the plant parts. $Y_{P}$ is the dry matter yield of grain yield $\left(\mathrm{g} \mathrm{m}^{-2}\right.$ years ${ }^{-1}$ ). The grain yield data were compiled from agricultural statistical yearbook of Beijing, Tianjin, Hebei,
Shandong and Henan province, respectively. As we use wheat and maize only, we assumed the $\mathrm{C}$ concentration of all plant parts is $400 \mathrm{~g} \mathrm{~kg}^{-1}$.

In fact, the portion of the fractions returned into the soil varied with time, for which we introduced the parameter $\mathrm{S}$ to account for it. Typically, by default: $S_{G}=0, S_{S}$ changed with different periods (Table S3 in detail). $S_{R}=1$ (Where $S_{G}, S_{S}$ and $S_{R}$ are the proportions of $\mathrm{C}$ in grain yield, straw, and rootderived $\mathrm{C}$, respectively).

$$
C_{1}=C_{G} \times S_{G}+C_{S} \times S_{S}+C_{R} \times S_{R}
$$


Where $C_{i}$ is the annual OC input to soil $\left(\mathrm{g} \mathrm{m}^{-2}\right)$, which is the sum of wheat and corn of the year.

Climate data: Mean annual temperature (MAT) and precipitation (MAP) from 1978 to 2010 were calculated using the data from 603 meteorological observation stations of the Chinese Meteorological Administration (CMA). The trend in the inter-annual change (as change per year) of these climatic variables was determined using Sen's nonparametric method (Gilbert 1987) by an excel template MAKESENS (developed by salmi et al. 2002, http://en.ilmatieteenlaitos.fi/makesens). Sen's method was used for cases in which the trend was assumed to be linear. The equation can be expressed as:

$f(t)=Q t+B$

where $t$ is time, $f(t)$ is the value in $t, \mathrm{Q}$ is the slope, and $\mathrm{B}$ is a constant. To obtain Q in Eq. (4), we first calculated the slopes of all data value pairs:

$Q_{i}=\left(x_{j}-x_{k}\right) /(j-k)$

where $\mathrm{j}>\mathrm{k}$.

If there are $n$ values of $x_{j}$ in the time series, we obtain as many as $N=n(n-1) / 2$ slope estimates $Q_{i}$. The Sen's estimator of slope is the median of these $\mathrm{N}$ values of $Q_{i}$. The $N$ values of $Q_{i}$ were ranked from smallest to largest, and the Sen's estimator is

$Q=Q[(N+1)]$, if $N$ is odd

or

$Q=\frac{1}{2}(Q[N / 2]+Q[N+2])$, if $N$ is even

A $100 \times(1-\alpha) \%$ two-sided confidence interval about the slope estimate was obtained by a nonparametric technique based on the normal distribution (Salmi et al. 2002). The method is valid for $n$ as small as 10 unless there are many ties. The changing trend of MAT over the past 32 years was named MAT_Q, with MAP_Q for MAP.

Topographical parameters: Based on the Digital Elevation Model (DEM) provided by The Shuttle Radar Topography Mission (SRTM, http://srtm.csi. cgiar.org/SELECTION/inputCoord.asp) with a resolution of $90 \mathrm{~m}$, different topographic parameters were calculated (Wilson and Gallant 2000) using ArcGIS 10.1 software (ESRI Inc., Redlands, CA). Primary terrain attributes, slope and curvature were obtained. The topographic wetness index (TWI) served as secondary parameters. The TWI was calculated using the following equation:

$\mathrm{TWI}=\operatorname{In}(S C A /$ tan $a)$

where SCA is the specific contributing area and $\alpha$ is the slope. The TWI is a topographic variable that reflects the potential soil moisture conditions (Beven and Kirkby 1978; Sorensen 2004).

Soil texture: Soil texture was determined by wet sieving and sedimentation according to the method of Köhn (Gee and Bauder 1986). Soil texture was determined using the sieve-pipette method (Pansu and Gautheyrou 2003) with three particles divisions: sand $(0.05-2 \mathrm{~mm})$, silt $(0.002-0.05 \mathrm{~mm})$ and clay $(<0.002 \mathrm{~mm})$.

Agricultural management practices: We collected county-scale agronomy data, including the grain yield $\left(\mathrm{kg} \mathrm{ha}^{-1}\right)$, fertilizer application per hectare $\left(\mathrm{kg} \mathrm{ha}^{-1}\right)$, irrigation area ratio (irrigated area/total area of cultivated land), and machine harvest ratio (machine harvest area/total area of cultivated land) from statistical yearbooks for each province (Hebei, Shandong, Henan) from 1978 to 2008. We further calculated the increasing rate of grain yield using Sen's method as in Eq. (5). We also used the crop rotation system of each sampling site. The crop rotation is a nominally scaled parameter. According to the different water resources for irrigation, we divided the sites into two parts, one from the Yellow River and the other one from the Hai River.

Soil chemical properties: These included the following: initial SOC content, soil total nitrogen (STN) content in the 1980s derived from soil monographs of each county, C/N ratio, and soil salt content in the 2010 s compiled from soil re-sampling campaigns.

Uncertainty analysis

As conditional stochastic simulations are suitable to assess spatial uncertainty by generating multiple alternative estimations while honoring the spatial structure of the sample data. We conducted an uncertainty analysis to account for the potential errors of Kriging interpolation using Monte-Carlo method (Brandimarte 2014: Ogle et al. 2003; Phillips and Marks 1996; Yang et al. 2012). Monte Carlo method can generate multiple results based on randomly selection of values from 
probability density functions (PDFs) (Ogle et al. 2003; Smith and heath 2001). According to the sampling locations in the 2010s, we extracted its corresponding Kriged estimate and estimation variance for the period of 1980s from the grid. As each grid has a distribution with the mean and standard deviation (SD) equal to the Kriged estimate and the square root of the estimation variance, respectively, we did a random sampling from the normal distribution for each corresponding site in the 1980s. By using the sampled values we calculated the average values for the counties in the 1980s and also for the difference between two sampling periods. Above processes were repeated 10000 times to estimate the mean value and obtain the 2.5 and 97.5 percentiles as a description of uncertainty (i.e., $95 \%$ confidence interval).

\section{Statistical analysis}

Descriptive statistics describe the soil data sets including mean, minimum and maximum values, median, interquartile range, outliers, skewness and kurtosis. The significance of the differences in SOC contents between the 1980 s and the 2010s for each county was tested with a $t$-test procedure for each county. Differences in the SOC changes in the four counties were tested with analysis of variance (ANOVA) using the SAS 9.3 statistical package (SAS Institute Inc. 2011). Statistical significance was determined at the $95 \%$ confidence level at $p<0.05$.

As the hierarchical sampling strategy adopted for the four specific counties, we chose a linear mixed model (LMM) to explore the driving factors in soil organic carbon changes over the last 30 years. An LMM is a parametric linear model for clustered or repeatedly measured data; these models are linear in their parameters, and the covariates, or independent variables, and may involve a mix of fixed and random effects (Brady et al. 2007). The data in an LMM can be correlated and the variability is not necessarily constant. LMMs have been used to model the SOC dynamics in a hierarchical sampling structure (Goidts et al. 2009; Maia et al. 2010; Suuster et al. 2012) and have a high prediction accuracy (Suuster et al. 2012). In our study, the SOC changes at all soil sampling sites were set as response variables. The four counties were considered as random effects in the model. The explanatory variables used as fixed effects were the agricultural management practices (i.e., crop rotation and irrigation resource), the initial soil physico-chemical properties (i.e., soil texture, SOC, STN, and C/N ratio in the 1980s), the topographic parameters (i.e., ASL, slope, curvature, and TWI), and related climatic parameters (i.e., mean annual temperature and its change rate, and mean annual precipitation and its change rate) (Table 1). The explanatory variables involved two category variables, such as the crop rotation and irrigation water source, and the rest were continuous variables (Table 1). After modelling, a 10-fold cross-validation method was used for model validation. The mean error (ME) and the root mean square error of prediction (RMSEP) were calculated to assess the model performance. This statistical analysis was realized using "nlme" (Pinheiro et al. 2014) and "DAAG" packages (John and Braun 2014) in R 3.1.2 (R Core Team 2014).

A multiple linear regression model (stepwise) was used to clarify the variables driving the SOCC on a regional scale. Explanatory variables were the grain yield increase rate (Yield_increase), the initial SOC values and related climatic variables, such as MAT,

Table 1 Variables used in the linear mixed models performed at the site level and multiple linear regression analysis performed at the county scale

\begin{tabular}{|c|c|c|c|}
\hline \multirow[t]{2}{*}{ Method } & \multirow[t]{2}{*}{ Dependent variable } & \multicolumn{2}{|l|}{ Explanatory variables } \\
\hline & & Continuous & Categorical \\
\hline Linear mixed models & SOCC & $\begin{array}{l}\text { SOC_1980, STN_1980, C/N_1980, ASL, } \\
\text { Salt, Slope, Curvature, TWI, Sand, Silt, } \\
\text { Clay, MAP_Q, MAT_Q }\end{array}$ & Rotation, Irrigation_resource \\
\hline Multiple linear regression & SOCC rate & $\begin{array}{l}\text { SOC_1980, Yield_increase, MAP, MAT, } \\
\text { MAT_Q, MAP_Q }\end{array}$ & \\
\hline
\end{tabular}

SOC_1980, SOC content in the 1980s ( $\left.\mathrm{g} \mathrm{kg}^{-1}\right)$; STN_1980, soil total nitrogen in the $1980 \mathrm{~s}\left(\mathrm{~g} \mathrm{~kg}^{-1}\right)$; C/N_1980, C-to-N ratio in the 1980s; ASL, above sea level (m); Salt, soil salt content in 2010 (\%); Slope, the slope of the land surface; TWI topographic wetness index, Curvature curvature of the land surface, Sand, Silt, and Clay, particle content of soil (\%); MAT mean annual temperature $\left({ }^{\circ} \mathrm{C}\right)$; MAP, mean annual precipitation (mm); MAT_ $Q$ annual rate of change of MAT $\left({ }^{\circ} \mathrm{C}\right), M A P \_Q$ annual rate of change of MAP (mm), Rotation crop rotation system 
MAP, MAT_Q, and MAP_Q. The dependent variable was the SOCC rate. Before the model was carried out, a correlation analysis was conducted among these variables to detect their relationships. This statistical analysis was realized using SAS 9.3 (SAS Institute Inc. 2011)

\section{Results}

SOC dynamics from the 1980 s to the 2010 s in the NCP

We collected published articles that focused on the SOC dynamics or agricultural soil fertility monitoring over multiple time scales ranging from 8 to 30 years. The SOC content shifted from $5.55 \pm 1.28 \mathrm{~g} \mathrm{~kg}^{-1}$ during $1977-1982$ to $8.71 \pm 1.22 \mathrm{~g} \mathrm{~kg}^{-1}$ during $2008-2012$. Taking 30 years as a time span, the change rate of SOC content was $0.11 \mathrm{~g} \mathrm{~kg}^{-1}$ year ${ }^{-1}$, indicating that
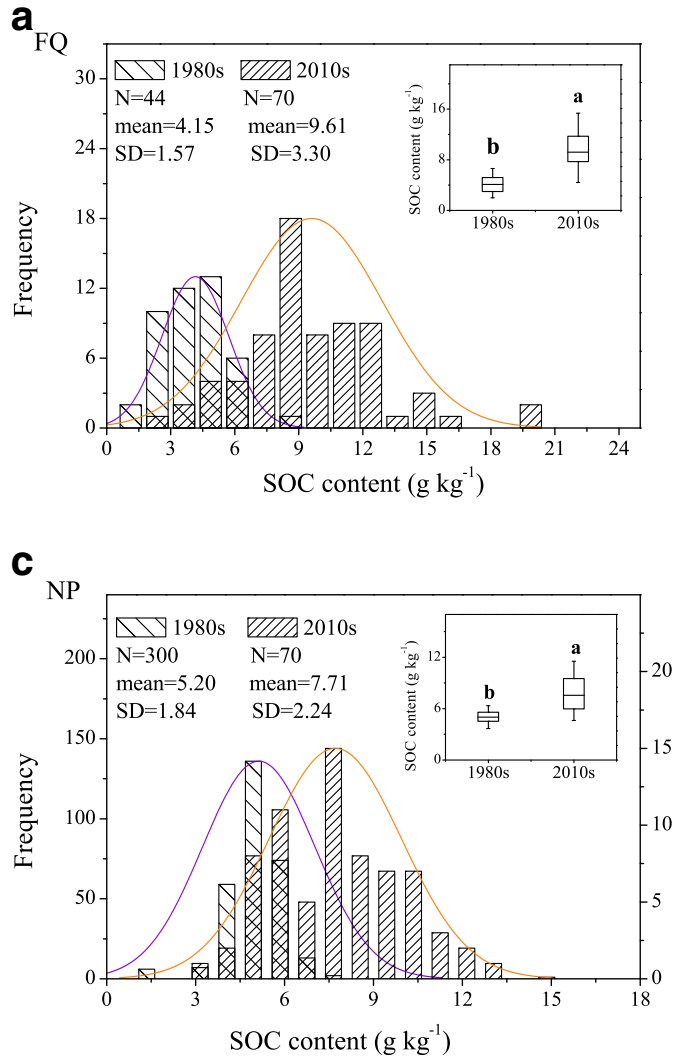

Fig. 3 Frequency distribution of soil organic carbon (SOC) changes across four counties over the two sampling periods from the 1980s to the 2010s in (a) Fengqiu (FQ), (b) Yucheng (YC), (c) Nanpi (NP), and (d) Kenli (KL). The inset in each panel shows an overall comparison of the SOC content between the two periods. the SOC content had been enhanced with high efficiency under the entire regional soil cover of the NCP over the last 30 years.

Asynchronous increase in the SOC content in the four typical counties

The right-shifted frequency distribution of the observations from the 1980 s to the 2010 s (Fig. 3), with the median ranging from 4.09 ( $\min 0.65-\max 9.12)$ to 9.20 (2.69-20.41) $\mathrm{g} \mathrm{kg}^{-1}$ in FQ, 5.08 (2.19-8.03) to 9.80 (4.24-13.70) $\mathrm{g} \mathrm{kg}^{-1}$ in YC, 5.02 (2.85-24.77) to 7.55 (9.15-12.68) $\mathrm{g} \mathrm{kg}^{-1}$ in NP, and $4.79(0.98-6.81)$ to 7.10 (1.87-12.55) $\mathrm{g} \mathrm{kg}^{-1}$ in KL, revealing an increasing trend in the organic carbon content of cropland topsoil in these four counties during the past three decades $(\mathrm{p}<0.05)$ (Fig. 3).

The SOC contents were low on average $\left(<5 \mathrm{~g} \mathrm{~kg}^{-1}\right)$ in the four counties in the 1980s (Table 2). While in the
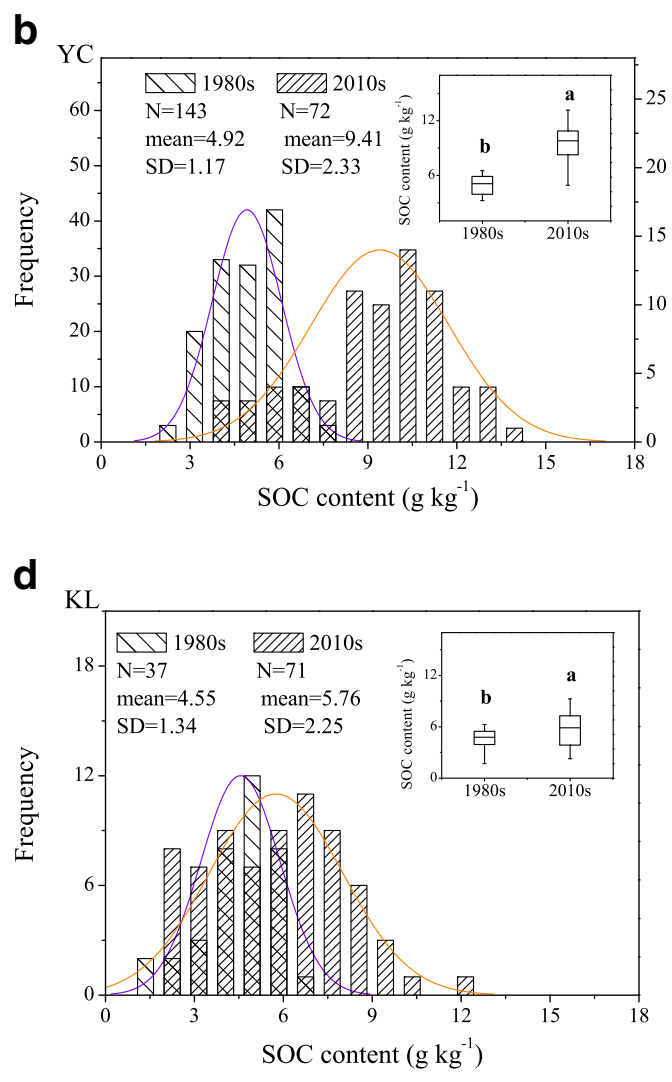

Letters denote the significance of the difference between them at a significance level 0.05 . ( $N$ number of sampling points; $S D$ : standard deviation; mean: average value of SOC content in each sampling period) 
2010s, the SOC content varied from $5.76 \mathrm{~g} \mathrm{~kg}^{-1}$ in $\mathrm{KL}$ to $9.61 \mathrm{~g} \mathrm{~kg}^{-1}$ in FQ (Table 2). Consequently, FQ and YC had a higher rate of SOCC, more than $0.15 \mathrm{~g} \mathrm{~kg}^{-1}$ year $^{-1}$, while NP and KL were at a low level that less than $0.10 \mathrm{~g} \mathrm{~kg}^{-1}$ year $^{-1}(\mathrm{p}<0.05)$ (Table 2). Compared to the historical sampling sites, $95.7 \%$ of the contemporary SOC have increased linearly in FQ with a slope of $2.24\left(r^{2}=0.87, p<0.001\right)$, an increase of $98.6 \%$ was found in $\mathrm{YC}$ with a slope of $1.89\left(r^{2}=0.93, p<0.001\right)$, an increase of $91.4 \%$ with $1.55\left(r^{2}=0.93, p<0.001\right)$ in $\mathrm{NP}$, and an increase of $73.2 \%$ with $1.23\left(r^{2}=0.79\right.$, $p<0.001$ ) in KL (Fig. S1). As a consequence, the SOC change showed a spatial heterogeneity across this area from the 1980 s to the 2010 s.

Controls on topsoil SOC change in the last 30 years

The amount of annual OC input into the soil increased by $148 \%$ from $439 \pm 31 \mathrm{~g} \mathrm{~m}^{-2}$ in the first period (19781982) to $1090 \pm 169 \mathrm{~g} \mathrm{~m}^{-2}$ in the recent period (20042008). The synchronous dynamic between the SOC content and the OC input in the croplands indicating that SOC accumulated in the NCP might mainly derive from the increase in OC input in the last three decades.

The linear mixed model showed that only a small part of variables $(<=4)$ remained significant $(p<0.05)$ when modelling the change in SOC at the sampling-site level (Table 3). The clay fraction and the crop rotation system had positive effects on the change in SOC. The SOC accumulation rate of cropland with wheat-maize rotation were significantly higher $(p<0.01)$ than that with annual cotton system. However, the initial value in the 1980s (SOC_1980) and the mean annual temperature change (MAT_Q) had negative effects on the SOCC. These fixed factors in the model alone can explain $31 \%$ of the variation of the SOCC during the last 30 years. The model performed well ( $\mathrm{RMSEP}=2.48 \mathrm{~g} \mathrm{~kg}^{-1}$ ) by checking with $\mathrm{k}$-fold validation method $(\mathrm{k}=10)$ (Fig. 4a) (Fig. 5).

Correlation matrices were calculated to identify the parameters related to the SOCC at the county level (Table S2). Generally, strong correlations $(p<0.01)$ were found between SOCC and the grain yield enhancement rate (Yield_increase, $r=0.79$ ), the initial value in the 1980s (SOC_1980, $r=-0.55$ ), and mean annual temperature change (MAT_Q, $r=-0.70$ ). However, for detecting the driving factor of the SOCC, the only parameter remained was Yield_increase after the stepwise linear regression at a significance level of $p<0.05$ (Table 4), while the SOC_1980 and MAT_Q were marginally significant $(p<0 . \overline{15})$ in the model. All of these values were at the county level. The multiple linear regression resulted in an adj- $\mathrm{R}^{2}$ of $0.73(p<0.001)$. The grain yield enhancement rate per hectare of the county corresponded well to its SOCC over the past three decades, of which the partial $\mathrm{R}^{2}$ of the model was 0.62 (Table 4).

\section{Discussion}

SOC evolutions during the last 30 years

Numerous studies have demonstrated that SOC sequestration was influenced by extra organic $\mathrm{C}$ input, but the magnitude and even the direction of this response varied among studies. We found that SOC content increased by $56.9 \%$ (from 5.55 to $8.71 \mathrm{~g} \mathrm{~kg}^{-1}$ ) together with organic $\mathrm{C}$ input during the last 30 years in the NCP (Fig. 2). Similarly, Cai and Qin (2006) and Liu et al. (2014)

Table 2 Soil organic carbon (SOC) content $(0-20 \mathrm{~cm})$ and its changes among the four typical counties during the last 30 years from $1980 \mathrm{~s}$ to 2010 s

\begin{tabular}{|c|c|c|c|c|}
\hline County & SOC1980s $\left(\mathrm{g} \mathrm{kg}^{-1}\right)$ & SOC2010s $\left(\mathrm{g} \mathrm{kg}^{-1}\right)$ & $\operatorname{SOCC}\left(\mathrm{g} \mathrm{kg}^{-1}\right)$ & SOCC rate $\left(\mathrm{g} \mathrm{kg}^{-1}\right.$ year $\left.{ }^{-1}\right)$ \\
\hline FQ & $4.08[3.72,4.46] \mathrm{b}$ & $9.61[8.69,10.52] \mathrm{a}$ & $5.52[5.15,5.88] \mathrm{a}$ & $0.18[0.17,0.20] \mathrm{a}$ \\
\hline $\mathrm{YC}$ & $4.92[4.77,5.07] \mathrm{a}$ & $9.41[8.77,10.04] \mathrm{a}$ & $4.49[4.34,4.64] \mathrm{b}$ & $0.15[0.14,0.15] \mathrm{b}$ \\
\hline NP & $4.96[4.91,5.16] \mathrm{a}$ & $7.71[7.09,8.33] b$ & $2.75[2.70,2.80] \mathrm{c}$ & $0.09[0.09,0.09] \mathrm{c}$ \\
\hline KL & $4.21[4.06,4.36] \mathrm{b}$ & $5.76[5.14,6.37] \mathrm{c}$ & $1.52[1.37,1.69] \mathrm{c}$ & $0.05[0.05,0.06] \mathrm{c}$ \\
\hline
\end{tabular}

Values in parenthesis denote $95 \%$ confidence intervals $\left(\mathrm{g} \mathrm{kg}^{-1}\right)$ of the means estimated by Monte-Carlo approach (10000 simulations), which is used to quantify uncertainties derived from spatial interpolation for the period $1980 \mathrm{~s}$. While the intervals that for the $2010 \mathrm{~s}$ were calculated by our sampling measurements during the 2010s. SOC1980s and SOC2010s denote SOC content of the two sampling periods, respectively; different letters indicate significant difference between them $(\mathrm{a}=0.05)$ 
Table 3 Results of the type III tests of fixed effects from the linear mixed effect model

\begin{tabular}{|c|c|c|c|c|c|c|c|c|c|c|c|}
\hline Variable & & Estimate & Std.Error & numDF ${ }^{\mathrm{e}}$ & $\operatorname{denDF}$ & F-value & t-value & p-value & adj. $\mathrm{R}^{2}$ conditional $^{\mathrm{a}}$ & $\mathrm{ME}^{\mathrm{b}}$ & RMSEP $^{\mathrm{c}}$ \\
\hline (Intercept) & & 5.62 & 1.55 & 1 & 273 & 587.61 & 3.61 & $<0.00$ & 0.31 & $<0.00$ & 2.48 \\
\hline Clay & & 0.09 & 0.02 & 1 & 273 & 29.59 & 4.92 & $<0.00$ & & & \\
\hline \multirow[t]{4}{*}{ Rotation $^{\mathrm{d}}$} & & & & 3 & 273 & 24.73 & & $<0.01$ & & & \\
\hline & RotationO & 1.08 & 0.79 & & & & 1.15 & 0.17 & & & \\
\hline & RotationWM & 2.06 & 0.62 & & & & 3.08 & $<0.00$ & & & \\
\hline & RotationWMC & 0.75 & 0.66 & & & & 0.96 & 0.33 & & & \\
\hline SOC_1980 & & -0.58 & 0.16 & 1 & 273 & 15.39 & -3.12 & $<0.00$ & & & \\
\hline MAT_Q & & -79.06 & 29.88 & 1 & 273 & 7.83 & -2.80 & $<0.01$ & & & \\
\hline
\end{tabular}

${ }^{a}$ adj. $R^{2}$ conditional, $\mathrm{R}^{2}$ of the model without random effects

${ }^{\mathrm{b}} M E$ mean error expressed in $\mathrm{g} \mathrm{kg}^{-1}$ for the change in SOC

${ }^{\mathrm{c}}$ RMSEP root mean square error of prediction calculated on the cross-validation sets after the model calibration with the data. RMSEP is expressed in $\mathrm{g} \mathrm{kg}^{-1}$ for the change in SOC

${ }^{\mathrm{d}}$ Rotation RotationWMC, annual wheat or maize with cotton; RotationWM, dual-crop system of wheat-maize rotation; RotationO, other plants (i.e., vegetation)

${ }^{\mathrm{e}}$ numDF, denDF The $\mathrm{F}$ distribution is the ratio of two estimates of variances. Therefore it has two parameters, the degrees of freedom of the numerator (numDF) and the degrees of freedom of the denominator (denDF)

demonstrated a significant linear relationship between organic C input and SOC content based on a metaanalysis of 176 published studies on straw return. Since the "Reform and Opening up" strategy of China in 1978, the increase in chemical fertilization and improved agro-management practices (Table S4) have led to dramatic increase of crop yield over the last three decades. Additionally, with improved living conditions and ban of the straw burning, much of the residues were returned to the field rather than used as fuel or feed for a

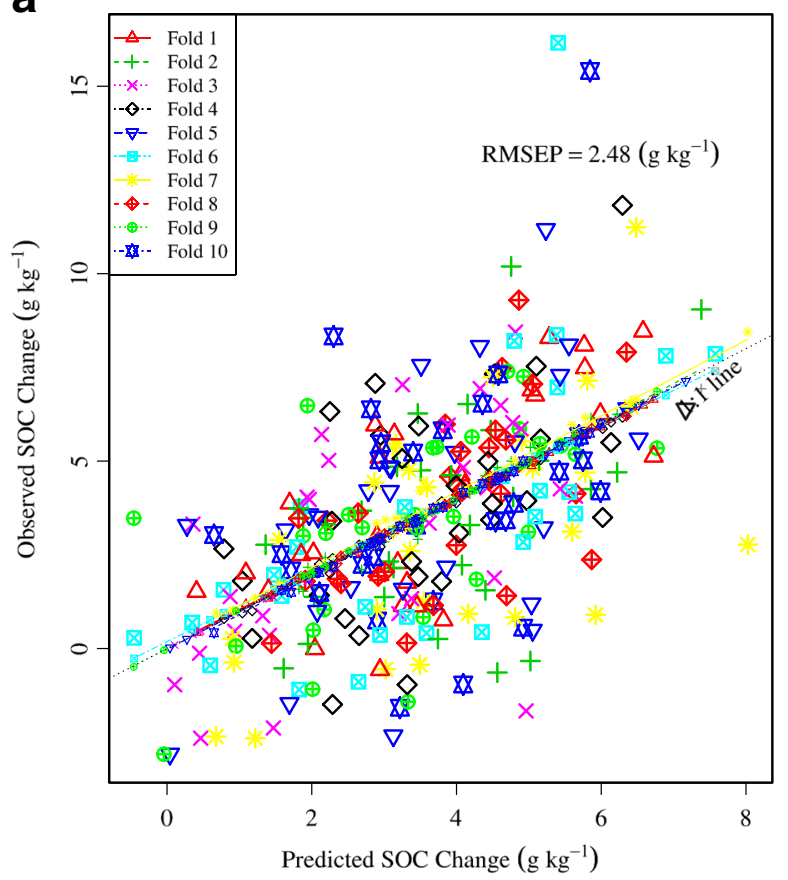

b

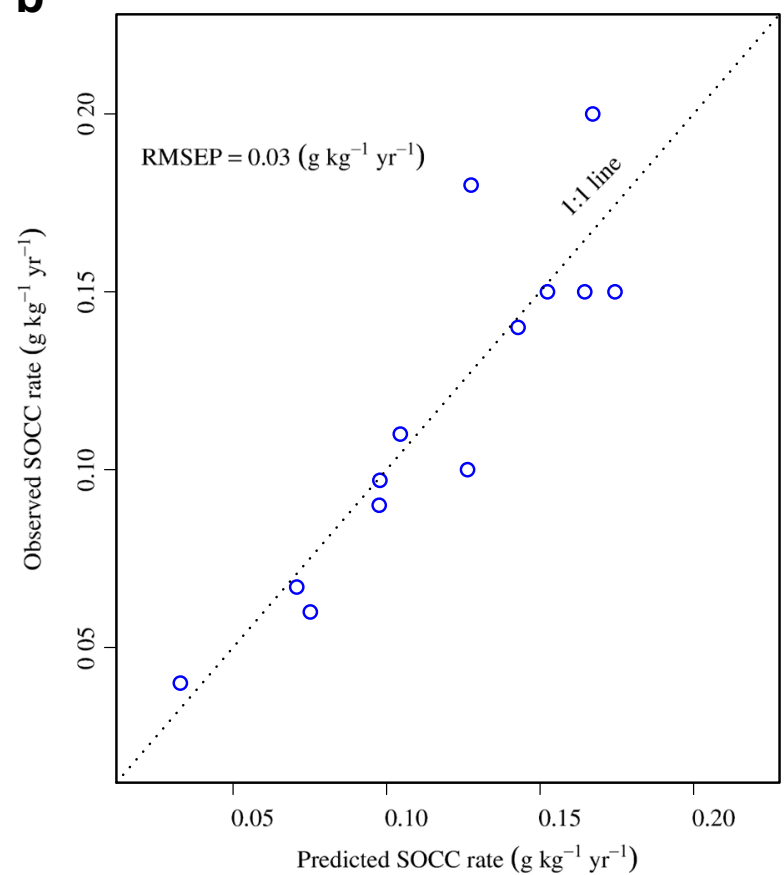

Fig. 4 Validation results for the modelling of the change in SOC at the site level (a) and in the SOCC rate on a county level (b). RMSEP, root mean square error of prediction (in $\mathrm{g} \mathrm{kg}^{-1}$ for the SOCC and $\mathrm{g} \mathrm{kg}^{-1}$ year $^{-1}$ for the SOCC rate) 
Fig. 5 Dynamics of organic carbon input into soils by crop biomass return; SOC content at different phases in the NCP. Calculation parameters are in Table S3

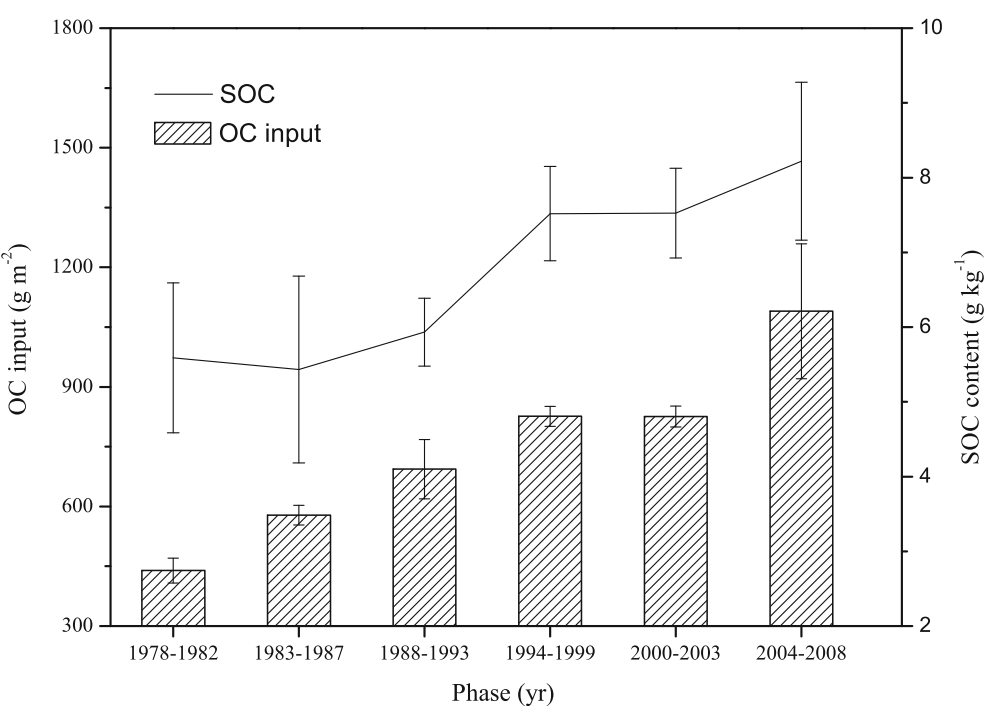

domestic livestock in the early 1980s (Cai and Qin 2006). Furthermore, $C$ input (crop residues) enhances soil nutrient availability. Even in small quantities, residues can be a long-term complement for the nutrient supply and in turn simulate $\mathrm{C}$ sequestration due to increased crop rhizodeposition (Kuzyakov and Schneckenberger 2004). So, the agricultural policy (i.e., subsidy, food price, etc.) and enhanced crop yield due to improved management practices made the large amount of OC (crop residue) returning to the soils possible.

The soil $\mathrm{C}$ containing capacity is essentially determined by the steady state $\mathrm{C}$ level under a specific management-soil-climate condition, but the efficiency of agricultural management practices to store SOC is highly time-dependent and influenced by the saturation deficit (Stewart et al. 2008; 2009). As in particular northern China had a low SOC level in the early $1980 \mathrm{~s}\left(4.62 \pm 1.15 \mathrm{~g} \mathrm{~kg}^{-1}\right.$; Cheng et al. 2005), the $C$ input increased dramatically from 439 $\pm 31\left(\mathrm{~g} \mathrm{~m}^{-2}\right)$ in 1978 to $1090 \pm 169\left(\mathrm{~g} \mathrm{~m}^{-2}\right)$ in 2008 . At the same time mechanization (Table S4) enabled a change of the straw processing from surface disposal to incorporation into the soil. The latter method has a higher $\mathrm{C}$ accumulation efficiency (Liu et al. 2014). The average efficiency of carbon sequestrated in the NCP (1980s-2000s) was $0.11 \mathrm{~g} \mathrm{~kg}^{-1}$ year $^{-1}$, which was 1.97 and 1.76 times higher than that of Chinese croplands $\left(0.056 \mathrm{~g} \mathrm{~kg}^{-1}\right.$ year $\left.{ }^{-1}\right)$ and upland soils (0.062 $\mathrm{g} \mathrm{kg}^{-1}$ year $^{-1}$ ) (Fig. 6), respectively. It was even slightly faster than that of paddy soils $\left(0.099 \mathrm{~g} \mathrm{~kg}^{-1}\right.$ year $\left.^{-1}\right)$, which were considered to be more efficient in sequestrating carbon than upland soils (Pan et al. 2010; Pan et al. 2003a; Qin et al. 2013; Sun et al. 2010). Therefore, the NCP might be the region with the fastest SOC accumulation rate during the last three decades. This is consistent with the result by Yan et al. (2011), who stated that the largest increase in SOC occurred in Fluvisols $(+30.5 \%)$ in the period from 1978 to 1982 to 2007-2008 among soil types in China. The low initial $\mathrm{C}$ content and large amount of $\mathrm{C}$ input that followed the enhanced crop productivity facilitated the high $\mathrm{C}$ sequestration.

Table 4 Results of type III tests of multiple linear regression analysis

\begin{tabular}{lllllllll}
\hline Variable & Estimate & Std.Error & Partial R & model R & F-value & p-value & adj.R & RMSE \\
\hline Intercept & 0.19 & 0.06 & & & 10.83 & 0.01 & 0.73 & 0.03 \\
Yield_increase & $3.05 \mathrm{E}-4$ & $1.22 \mathrm{E}-4$ & 0.62 & 0.62 & 6.28 & 0.03 & 13 \\
SOC_1980 & -0.01 & 0.01 & 0.10 & 0.72 & 3.92 & 0.08 & \\
MAT_Q & -1.87 & 1.06 & 0.07 & 0.79 & 3.13 & 0.11 & \\
\hline
\end{tabular}


Fig. 6 Comparison of SOC rate of change between croplands in the NCP and China during the period 1980s-2000s. Vertical line represents the values ranging from the lower to the upper. Horizontal line is the average value corresponding to land use in the bottom. Paddy is cropland where irrigated rice grown and upland is that where other crops are planted

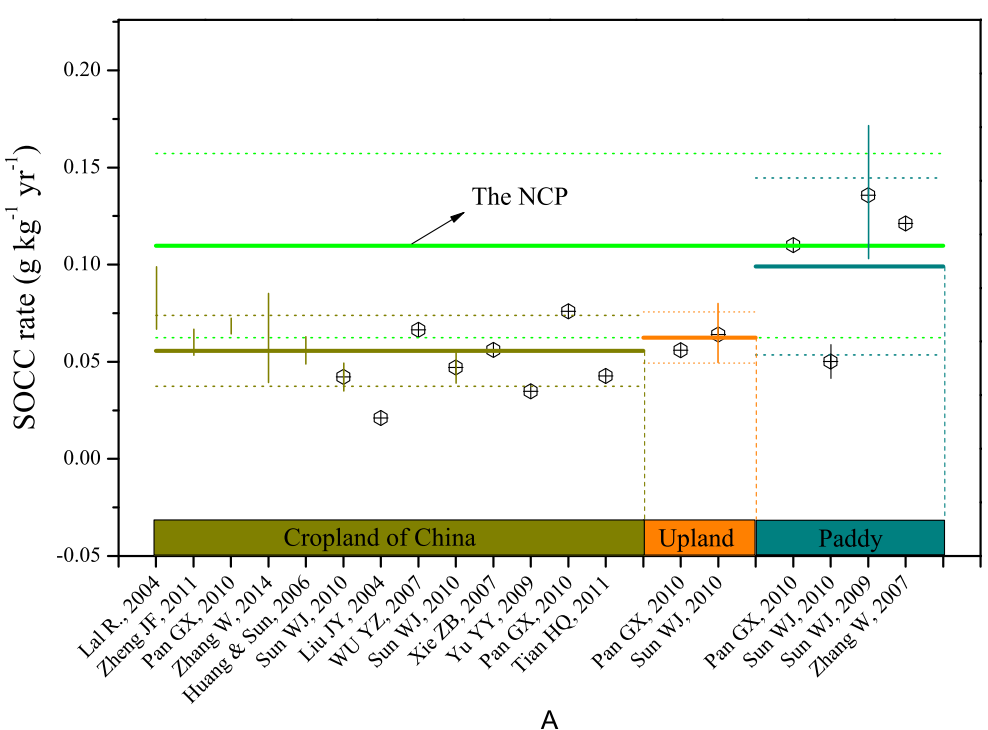

A
Effects of management practices and environmental factors on SOC

Human activities and environmental factors mutually influence carbon accumulation by affecting its input and output processes. Although overall $\mathrm{C}$ sequestration rate are high, the spatial pattern of SOC evolution is heterogeneous (Table 2), which reflects an imbalance of influences from natural and anthropogenic controls. With years of government facilitation, agricultural investments in chemical fertility, irrigation area and agricultural machinery increased over the last 30 years by 618,26 and $832 \%$, respectively (agricultural statistical yearbooks of Shandong, Hebei and Henan provinces, 1978-2008) (Table S4). The cultivation environment was therefore immensely improved. Some places reached a high crop productivity of more than $15000 \mathrm{~kg} \mathrm{ha}^{-1}$ (Zhang et al. 2011) compared to less than $3000 \mathrm{~kg} \mathrm{ha}^{-1}$ in the early $1980 \mathrm{~s}$. Soil salinization was no longer the main agro-impeding factor (Fang et al. 2005). Without nutrient and water deficiencies (Wang et al. 2014), FQ and $Y C$ had the highest $C$ sequestration efficiencies over $0.15 \mathrm{~g} \mathrm{~kg}^{-1} \mathrm{y}^{-1}$. NP is located in the eastern Haihe Plain suffering the serious water deficiency which impeded its agricultural development. For instance, the water table in Quzhou (in the Hebei province) decreased from $4.72 \mathrm{~m}$ in 1981 to $9.81 \mathrm{~m}$ in 1999 , which was far below the sea level in 2005a (Liu et al. 2005), consequently causing serious environmental problems due to ground subsidence and seawater intrusion (Mo et al. 2006). KL is located in the estuary of the
Yellow River; due to the universal distribution of soil salinity in this district, $78 \%$ of the sampling points in KL from our survey data were planted only with cotton, which has less organic material remaining after harvest. The differences in crop rotation between KL and the other three counties, primarily induced by soil salinity, resulted in a different $\mathrm{C}$ input and hence SOC accumulation rate (Table 3 ).

Much attention has been paid to the effect of climate change on SOC accumulation in croplands, and the different results reveal that it is difficult to draw uniform conclusions (Bellamy et al. 2005; Ciais et al. 2011). Wang et al. (2014) found no strong correlation between the SOCC and climatic variables (MAT, MAP) in the NCP by employing a calibrated Agro-C model, which is consistent with our results (Table 4 and A.2). However, the increasing temperature trend (MAT_Q) appears to be a negative factor for $\mathrm{C}$ sequestration (Table 1 and $\mathrm{S} 2$ ) at the site level. This may be due to the higher microbial activity at higher temperatures, subsequently causing more C loss due to decomposition (Yang et al. 2007). However, from the county-level analysis (Table 4), the temperature effect on SOC dynamics was not significant in the multiple linear regression $(p=0.11)$. Nevertheless, the climate changes in the NCP (Fig. S2) might indirectly affect SOC by stimulating an increase in crop NPP (Tao and Zhang 2013; Tao et al. 2014). Therefore, we can infer that climate effects are of minor importance in agricultural soils because agromanagement options counteract them to a certain extent (Wiesmeier et al. 2013; Xu et al. 2009); improvement in 
management practices should be a more important factor in the SOCC than the scenarios of climate change, which is consistent with the conclusions of Thomson et al. (2006) and Yu et al. (2009). The role of soils in sequestering $\mathrm{C}$ as affected by climatic variables needs to be identified over a long time scale, and modelling could be a promising mean to detect the effect of climate change on SOC dynamics in agricultural ecosystems.

Many previous studies have proposed a relationship between initial organic matter or soil particle-size fractions and its SOC sequestration efficiency (Bellamy et al. 2005; Hassink 1997; Post and Kwon 2000). From our analysis, SOCC had a slightly negative relationship with the initial SOC content in the 1980s (Tables 2 and 3 and S2) at both the site and county levels. Regardless of the climate scenario or the management option, the simulated data suggested that soils with low carbon content tend to accrue more $C$ than soils with high carbon content (Bellamy et al. 2005). Soils relatively rich in $\mathrm{C}$ may not accrue $\mathrm{C}$ because they may already close to the saturation level (Hassink 1996; Six et al. 2002) or because the simulated $C$ inputs are not large enough to offset the losses dictated by the decomposition rates (Thomson et al. 2006). It has been suggested that SOC is texture-dependent and highly correlated with the amount of fine particles (Angers et al. 2011; Arrouays et al. 2006; Hassink 1997). A positive effect was found between the SOCC and clay content (Table 3), which is consistent with Meersmans et al. (2011) and Goidts and van Wesemael (2007), who found that in spite of the significantly increased OC input in northern Belgium, only the clay textured cropland soils were characterized by an important increase in SOC between 1960 and 2006. While clay protection is generally accepted as a control on the SOC level in natural soils, Pan et al. (2003b) argued that only 10$30 \%$ of the regional variation in SOC across China was explained by the clay content and that mineral protection was not generally true for the SOC levels of China's cropland soils.

Adaptive management practices for SOC sequestration in the future

The SOC content was obviously enhanced during the last 30 years in the NCP, while it remained at a low level compared to other agricultural regions in China. Meanwhile, the general status of SOC content in
China is also falling behind (Batjes 1996). These conditions suggested a huge $\mathrm{C}$ sequestration potential for the soils (Fluvisols) in the NCP. This potential could be realized by adapting RMPs, which could both enhance soil quality and keep yield production steady under future climate scenarios.

The increasing water deficits associated with subsequent problems threatened the sustainability of agricultural production in this area (Hu et al. 2005). Recent studies have shown that climate change could greatly influence the water crisis situation in the NCP (Tao et al. 2005). Fig. S2 depicts the climate change trend: an increase in annual temperature along with a decrease in precipitation in the northern region, aggravates the water deficiency (Fu et al. 2004; Yang et al. 2004). Improving the water use efficiency (WUE) of the crops through construction projects and crop breeding technology is crucial to coping with the water shortage issue and to guarantee enough grain production to meet the food demands of the increasing population (Condon et al. 2004).

Increasing $\mathrm{N}$ fertilization has been a major part of improved agricultural practices and has contributed substantially to the increase in crop yield in the NCP from 1980 to 2000 (Ju et al. 2009). However, the annual application rate of synthetic $\mathrm{N}$ is more than $600 \mathrm{~kg} \mathrm{~N} \mathrm{ha}^{-1}$ in the NCP, which is far greater than crop demand and has resulted in a series of environmental problems (Guo et al. 2010). Wang et al. (2014) found that the positive effect of fertilizer on SOC accumulation did not last when $\mathrm{N}$ fertilization application rates exceeded $300 \mathrm{~kg} \mathrm{~N} \mathrm{ha}^{-1}$ in the NCP. In Australia, using an agricultural system model, Zhao et al. (2013) found negligible further increases in SOC when fertilization

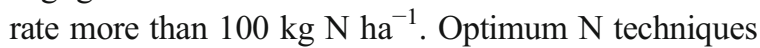
should be applied to substantially reduce $\mathrm{N}$ application and to maintain the yields demand to feed an increasing population, which preventing total $\mathrm{N}$ loss to the environment as well, aiming to establish sustainable agricultural systems (Ju et al. 2009).

An area of $4.4 \times 10^{5}$ ha (over $70 \%$ of the total) in the Yellow River Delta has been degraded due to salinity (Han et al. 2000; Xu 2000). Previous studies have found that the SOC content would be significantly increased with improved soil quality (i.e., salinity reduction) and agricultural management (i.e., freshwater addition). Yu et al. (2012) claimed that the Yellow River Delta will have great potential for SOC sequestration because of its low SOC content compared to other coastal regions in 
China (Dodla et al. 2008; Wang et al. 2007); moreover, anthropogenic activities have played a major role in the SOC dynamics in this area.

Acknowledgments This research was sponsored by the "Strategic Priority Research Program - Climate Change: Carbon Budget and Related Issues" of the Chinese Academy of Sciences (Grant No. XDA05050502). We thank the faculty of Yucheng comprehensive experimental station (CAS) for their excellent work of data collection and laboratory analysis. We are grateful to Dr. Xingliang $\mathrm{Xu}$ for constructive suggestions on this manuscript.

\section{References}

Angers DA, Arrouays D, Saby NPA, Walter C (2011) Estimating and mapping the carbon saturation deficit of French agricultural topsoils. Soil Use Manag 27:448-452. doi:10.1111/j. 1475-2743.2011.00366.x

Arrouays D, Saby N, Walter C, Lemercier B, Schvartz C (2006) Relationships between particle-size distribution and organic carbon in French arable topsoils. Soil Use Manag 22:48-51. doi:10.1111/j.1475-2743.2006.00020.x

Batjes NH (1996) Total carbon and nitrogen in the soils of the world. Eur J Soil Sci 47:151-163. doi:10.1111/j.1365-2389. 1996.tb01386.x

Bellamy PH, Loveland PJ, Bradley RI, Lark RM, Kirk GJD (2005) Carbon losses from all soils across England and Wales 1978-2003. Nature 437:245-248. doi:10.1038/ nature 04038

Beven KJ, Kirkby MJ (1978) A physically based, variable contributing area model of basin hydrology. Hydrol Sci Bull 24: 43-69

Bolinder MA, Janzen HH, Gregorich EG, Angers DA, VandenBygaart AJ (2007) An approach for estimating net primary productivity and annual carbon inputs to soil for common agricultural crops in Canada. Agric Ecosyst Environ 118:29-42

Brady TW, Kathleen BW, Andrzej TG (2007) Linear mixed models, a practical guide using statistical software. Taylor \& Francis Group. LLC, Boca Raton

Brandimarte P (2014) Introduction to Monte Carlo Methods. Handbook in Monte Carlo Simulation. Wiley

Cai ZC, Qin SW (2006) Dynamics of crop yields and soil organic carbon in a long-term fertilization experiment in the HuangHuai-Hai Plain of China. Geoderma 136:708-715. doi:10. 1016/j.geoderma.2006.05.008

Cheng WX, OuYang Z, Wu LF (2005) Agro-ecosystems in Huang Huai Hai Plain. In: HL Sun (ed) The ecosystems in China. Science Press, BeiJing (in Chinese)

Ciais P, Gervois S, Vuichard N, Piao SL, Viovy N (2011) Effects of land use change and management on the European cropland carbon balance. Glob Chang Biol 17:320-338. doi:10. 1111/j.1365-2486.2010.02341.x

Condon AG, Richards RA, Rebetzke GJ, Farquhar GD (2004) Breeding for high water-use efficiency. J Exp Bot 55:24472460. doi:10.1093/jxb/erh277
Cressie NAC (2015) Statistics for spatial data. Wiley

Davidson EA, Janssens IA (2006) Temperature sensitivity of soil carbon decomposition and feedbacks to climate change. Nature 440:165-173. doi:10.1038/nature04514

Dodla SK, Wang JJ, DeLaune DR, Cook R (2008) Denitrification potential and its relation to organic carbon quality in three coastal wetland soils. Sci Total Environ 407:471-480

Fang S, Chen XL, Fan ZD, Wan BL (2005) Comprehensive control of drought, waterlogging, salinity and saline groudwater and good circulation of eco-environment. South North Water Tran Water Sci Technolo 3:12-18

Fang Q, Yu Q, Wang E, Chen Y, Zhang G, Wang J, Li L (2006) Soil nitrate accumulation, leaching and crop nitrogen use as influenced by fertilization and irrigation in an intensive wheat-maize double cropping system in the North China Plain. Plant Soil 284:335-350. doi:10.1007/s11104-0060055-7

Fu GB, Chen SL, Liu CM, Shepard D (2004) Hydro-climatic trends of the Yellow River basin for the last 50 years. Clim Chang 65:149-178. doi:10.1023/B:CLIM.0000037491. 95395.bb

Gee GW, Bauder JW (1986) Particle-size analysis. In: Page AL (ed) Methods of soil analysis, part 1, physical and mineralogical methods. Soil Science Society of America, Wisconsin

Gilbert RO (1987) Statistical method for environmental pollution monitoring. Van Nostrand Reinhold, New York

Goidts E, van Wesemael B (2007) Regional assessment of soil organic carbon changes under agriculture in Southern Belgium (1955-2005). Geoderma 141:341-354. doi:10. 1016/j.geoderma.2007.06.013

Goidts E, van Wesemael B, Van Oost K (2009) Driving forces of soil organic carbon evolution at the landscape and regional scale using data from a stratified soil monitoring. Glob Chang Biol 15:2981-3000. doi:10.1111/j.1365-2486.2009.01940.x

Guo JH, Liu XJ, Zhang Y, Shen JL, Han WX, Zhang WF, Christie P, Goulding KWT, Vitousek PM, Zhang FS (2010) Significant acidification in major Chinese croplands. Science 327:1008-1010. doi:10.1126/science. 1182570

Han YZ, Tian LY, Xu XG (2000) A preliminary study on wetland ecosystem and its protection of Yellow River Delta. Environ Sci Technol 89:10-13

Hassink J (1996) Preservation of plant residues in soils differing in unsaturated protective capacity. Soil Sci Soc Am J 60:487491

Hassink J (1997) The capacity of soils to preserve organic C and N by their association with clay and silt particles. Plant Soil 191:77-87. doi:10.1023/a:1004213929699

Hu C, Delgado JA, Zhang X, Ma L (2005) Assessment of groundwater use by wheat (Triticum aestivum L.) in the Luancheng Xian region and potential implications for water conservation in the northwestern North China Plain. J Soil Water Conserv 60:80-88

Huang Y, Sun W (2006) Changes in topsoil organic carbon of croplands in mainland China over the last two decades. Chin Sci Bull 51:1785-1803. doi:10.1007/s11434-006-2056-6

Hutchinson JJ, Campbell CA, Desjardins RL (2007) Some perspectives on carbon sequestration in agriculture. Agric For Meteorol 142:288-302. doi:10.1016/j.agrformet.2006.03. 030 
IPCC (1996) Cliamte change 1995: the science of climate change. Contribution of working group I to the 2 nd assessment report of the IPCC. Cambridge University Press, Cambridge

Jobbagy EG, Jackson RB (2000) The vertical distribution of soil organic carbon and its relation to climate and vegetation. Ecol Appl 10:423-436. doi:10.2307/2641104

John HM, Braun WJ (2014) DAAG: data analysis and graphics data and functions. R Packag Version 1:20

Johnson JM-F, Allmaras RR, Reicosky DC (2006) Estimating source carbon from crop residues, roots and rhizodeposits using the national grain-yield database. Agron J 98:622. doi: 10.2134/agronj2005.0179

Ju XT, Xing GX, Chen XP, Zhang SL, Zhang LJ, Liu XJ, Cui ZL, Yin B, Christie P, Zhu ZL, Zhang FS (2009) Reducing environmental risk by improving $\mathrm{N}$ management in intensive Chinese agricultural systems. Proc Natl Acad Sci U S A 106: 3041-3046. doi:10.1073/pnas.0813417106

Kendy E, Gerard-Marchant P, Walter MT, Zhang YQ, Liu CM, Steenhuis TS (2003) A soil-water-balance approach to quantify groundwater recharge from irrigated cropland in the North China Plain. Hydrol Process 17:2011-2031. doi:10. 1002/hyp. 1240

Kuzyakov Y, Schneckenberger K (2004) Review of estimation of plant rhizodeposition and their contribution to soil organic matter formation. Arch Agron Soil Sci 50:115-132. doi:10. 1080/03650340310001627658

Lal R (2002) Soil carbon sequestration in China through agricultural intensification, and restoration of degraded and desertified ecosystems. Land Degrad Dev 13:469-478. doi: 10.1002/ldr.531

Lal R (2004a) Soil carbon sequestration impacts on global climate change and food security. Science 304:1623-1627. doi:10. 1126/science. 1097396

Lal R (2004b) Soil carbon sequestration to mitigate climate change. Geoderma 123:1-22. doi:10.1016/j.geoderma.2004. 01.032

Liu YH, Yu ZR, Zhang FR, Song CM, Liu Y (2005) Dynamic change of soil organic matter and its effecting factors at county level. Plant Nutr Fertil Sci 11(3):294-301 (in Chinese with English abstract)

Liu Y, Wang E, Yang X, Wang J (2010) Contributions of climatic and crop varietal changes to crop production in the North China Plain, since 1980s. Glob Chang Biol 16:2287-2299. doi:10.1111/j.1365-2486.2009.02077.x

Liu C, Lu M, Cui J, Li B, Fang CM (2014) Effects of straw carbon input on carbon dynamics in agricultural soils: a meta-analysis. Glob Chang Biol 20:1366-1381. doi:10.1111/gcb. 12517

Lobell DB, Burke MB, Tebaldi C, Mastrandrea MD, Falcon WP, Naylor RL (2008) Prioritizing climate change adaptation needs for food security in 2030. Science 319:607-610. doi: 10.1126/science. 1152339

Lu RK (1999) Analytical method of soil agricultural chemistry. China Agricultural Science and Technology Press, Beijing (in Chinese)

Lu F, Wang X, Han B, Ouyang Z, Duan X, Zheng H, Miao H (2009) Soil carbon sequestrations by nitrogen fertilizer application, straw return and no-tillage in China's cropland. Glob Chang Biol 15:281-305. doi:10.1111/j.1365-2486.2008. 01743.x
Lu W, Ding W, Zhang J, Li Y, Luo J, Bolan N, Xie Z (2014) Biochar suppressed the decomposition of organic carbon in a cultivated sandy loam soil: a negative priming effect. Soil Biol Biochem 76:12-21. doi:10.1016/j.soilbio.2014.04.029

Luo Y, Weng E (2011) Dynamic disequilibrium of the terrestrial carbon cycle under global change. Trends Ecol Evol 26:96104. doi:10.1016/j.tree.2010.11.003

Maia SMF, Ogle SM, Cerri CC, Cerri CEP (2010) Changes in soil organic carbon storage under different agricultural management systems in the Southwest Amazon Region of Brazil. Soil Tillage Res 106:177-184. doi:10.1016/j.still.2009.12. 005

Meersmans J, van Wesemael B, Goidts E, van Molle M, De Baets S, De Ridder F (2011) Spatial analysis of soil organic carbon evolution in Belgian croplands and grasslands, 1960-2006. Glob Chang Biol 17:466-479. doi:10.1111/j.1365-2486. 2010.02183.x

Mo XG, Lin ZH, Liu SX (2006) Spatial-temporal evolution and driving forces of winter wheat productivity in the Huang Huai Hai Region. J Nat Resour 21(3):449-457

Muller T, Hoper H (2004) Soil organic matter turnover as a function of the soil clay content: consequences for model applications. Soil Biol Biochem 36:877-888. doi:10.1016/j. soilbio.2003.12.015

Ogle SM, Breidt FJ, Eve MD, Paustian K (2003) Uncertainty in estimating land use and management impacts on soil organic carbon storage for US agricultural lands between 1982 and 1997. Glob Chang Biol 9:1521-1542. doi:10.1046/j.15298817.2003.00683.x

Pan GX, Li LQ, Wu LS, Zhang XH (2003a) Storage and sequestration potential of topsoil organic carbon in China's paddy soils. Glob Chang Biol 10:79-92. doi:10.1111/j.1365-2486. 2003.00717.x

Pan GX, Li LQ, Zhang XH, Dai JY, Zhou YC, Zhang PJ (2003b) Soil organic carbon storage of China and the sequestration dynamics in agricultural lands. Adv Earth Sci 18(4):609-618 (in Chinese with English abstract)

Pan G, Xu X, Smith P, Pan W, Lal R (2010) An increase in topsoil SOC stock of China's croplands between 1985 and 2006 revealed by soil monitoring. Agric Ecosyst Environ 136: 133-138. doi:10.1016/j.agee.2009.12.011

Pansu M, Gautheyrou J (2003) Handbook of soil analysis: mineralogical, organic and inorganic methods. Springer, Berlin

Paustian K, Cole CV, Sauerbeck D, Sampson N (1998) $\mathrm{CO}_{2}$ mitigation by agriculture: an overview. Clim Chang 40: 135-162. doi:10.1023/a:1005347017157

Peng SB, Huang JL, Sheehy JE, Laza RC, Visperas RM, Zhong XH, Centeno GS, Khush GS, Cassman KG (2004) Rice yields decline with higher night temperature from global warming. Proc Natl Acad Sci U S A 101:9971-9975. doi: 10.1073/pnas.0403720101

Phillips DL, Marks DG (1996) Spatial uncertainty analysis: propagation of interpolation errors in spatially distributed models. Ecol Model 91:213-229. doi:10.1016/0304-3800(95)001913

Pinheiro J, Bates D, DebRoy S, Sarkar D, R Core Team (2014) nlme: Linear and Nonlinear Mixed Models. 3.1-118 edn

Post WM, Kwon KC (2000) Soil carbon sequestration and landuse change: processes and potential. Glob Chang Biol 6:317327. doi:10.1046/j.1365-2486.2000.00308.x 
Qin ZC, Huang Y, Zhuang QL (2013) Soil organic carbon sequestration potential of cropland in China. Glob Biogeochem Cycles 27:711-722. doi:10.1002/gbc.20068

R Core Team (2014) R: a language and environment for statistical computing. R Foundation for Statistical Computing, Vienna, Austria. URL https://www.R-project. org/

Ren W, Tian HQ, Tao B, Huang Y, Pan SF (2012) China's crop productivity and soil carbon storage as influenced by multifactor global change. Glob Chang Biol 18:2945-2957. doi: 10.1111/j.1365-2486.2012.02741.x

Saby NPA, Arrouays D, Antoni V, Lemercier B, Follain S, Walter C, Schvartz C (2008) Changes in soil organic carbon in a mountainous French region, 1990-2004. Soil Use Manag 24: 254-262. doi:10.1111/j.1475-2743.2008.00159.x

Salmi T, Maatta A, Anttila P, Ruoho-Airola T, Amnell T (2002) Detecting trends of annual values of atmospheric pollutants by the Mann-Kendall test and Sen's Slope estimates - the excel template application MAKESENS. In: Publications on air quality, No. 31. Finish Meteorological Institute, Helsinki, Finland.

SAS Institute Inc (2011) Base $\mathrm{SAS}^{\circledR} 9.3$ procedures guide. SAS Institute Inc, Cary, NC

Six J, Conant RT, Paul EA, Paustian K (2002) Stabilization mechanisms of soil organic matter: implications for C-saturation of soils. Plant Soil 241:155-176. doi:10.1023/ a:1016125726789

Smith JE, Heath LS (2001) Identifying influences on model uncertainty: an application using a forest carbon budget model. Environ Manag 27:253-267. doi:10.1007/s002670010147

Smith P, Powlson DS, Glendining MJ, Smith JU (1997) Potential for carbon sequestration in European soils: preliminary estimates for five scenarios using results from long-term experiments. Glob Chang Biol 3:67-79. doi:10.1046/j.1365-2486. 1997.00055.x

Smith P, Martino D, Cai Z, Gwary D, Janzen H, Kumar P, McCarl B, Ogle S, O'Mara F, Rice C, Scholes B, Sirotenko O, Howden M, McAllister T, Pan G, Romanenkov V, Schneider U, Towprayoon S (2007) Policy and technological constraints to implementation of greenhouse gas mitigation options in agriculture. Agric Ecosyst Environ 118:6-28. doi: 10.1016/j.agee.2006.06.006

Sorensen P (2004) Immobilisation, remineralisation and residual effects in subsequent crops of dairy cattle slurry nitrogen compared to mineral fertiliser nitrogen. Plant Soil 267:285296. doi:10.1007/s11104-005-0121-6

Stewart CE, Plante AF, Paustian K, Conant RT, Six J (2008) Soil carbon saturation: linking concept and measurable carbon pools. Soil Sci Soc Am J 72:379-392. doi:10.2136/ Sssaj2007.0104

Stewart CE, Paustian K, Conant RT, Plante AF, Six J (2009) Soil carbon saturation: implications for measurable carbon pool dynamics in long-term incubations. Soil Biol Biochem 41: 357-366. doi:10.1016/j.soilbio.2008.11.011

Sun W, Huang Y, Zhang W, Yu Y (2010) Carbon sequestration and its potential in agricultural soils of China. Global Biogeochemical Cycles 24. doi: 10.1029/2009gb003484

Suuster E, Ritz C, Roostalu H, Kolli R, Astover A (2012) Modelling soil organic carbon contentration of mineral soils in arable land using legacy soil data. Eur J Soil Sci 63:351359
Tao F, Zhang Z (2013) Climate change, wheat productivity and water use in the North China Plain: a new super-ensemblebased probabilistic projection. Agric For Meteorol 170:146165. doi:10.1016/j.agrformet.2011.10.003

Tao FL, Yokozawa M, Hayashi Y, Lin ED (2005) A perspective on water resources in China: Interactions between climate change and soil degradation. Clim Chang 68:169-197. doi: 10.1007/s10584-005-6013-1

Tao F, Zhang Z, Xiao D, Zhang S, Rotter RP, Shi W, Liu Y, Wang M, Liu F, Zhang H (2014) Responses of wheat growth and yield to climate change in different climate zones of China, 1981-2009. Agric For Meteorol 189:91-104. doi:10.1016/j. agrformet.2014.01.013

The World Bank (2012) World development indicators. The Wolrd Bank, Washington, DC

Thomson AM, Izaurralde RC, Rosenberg NJ, He XX (2006) Climate change impacts on agriculture and soil carbon sequestration potential in the Huang-Hai Plain of China. Agric Ecosyst Environ 114:195-209. doi:10.1016/j.agee.2005.11. 001

Vukicevic T, Braswell BH, Schimel D (2001) A diagnostic study of temperature controls on global terrestrial carbon exchange. Tellus Ser B-Chem Phys Meteorol 53:150-170. doi:10.1034/ j.1600-0889.2001.d01-13.x

Wang A, Chen J, Li D, Zhou Z (2007) Spatial variations of carbon and nitrogen in Coastal Wetland Sediments of Quanzhou Bay in China. Environ Sci 28:2361-2368 (in Chinese with English abstract)

Wang G, Li T, Zhang W, Yu Y (2014) Impacts of agricultural management and climate change on future soil organic carbon dynamics in North China Plain. Plos One 9. doi: 10. 1371/journal.pone.0094827

West TO, Post WM (2002) Soil organic carbon sequestration rates by tillage and crop rotation: a global data analysis. Soil Sci Soc Am J 66:1930-1946

West TO, Six J (2007) Considering the influence of sequestration duration and carbon saturation on estimates of soil carbon capacity. Clim Chang 80:25-41. doi:10.1007/s10584-0069173-8

Wiesmeier M, Prietzel J, Barthold F, Sporlein P, Geuss U, Hangen E, Reischl A, Schilling B, von Lutzow M, Kogel-Knabner I (2013) Storage and drivers of organic carbon in forest soils of southeast Germany (Bavaria) - Implications for carbon sequestration. For Ecol Manag 295:162-172. doi:10.1016/j. foreco.2013.01.025

Wilson JP, Gallant J (2000) Terrain analysis: principle and application. Wiley, Singapore

Xie ZB, Zhu JG, Liu G, Cadisch G, Hasegawa T, Chen CM, Sun HF, Tang HY, Zeng Q (2007) Soil organic carbon stocks in China and changes from 1980s to 2000s. Glob Chang Biol 13:1989-2007

Xu XG (2000) The applicable Eco-agricultural models and territorial structure of agriculture in the Yellow River Delta. Sci Geogr Sin 20:27-32

Xu XW, Pan GX, Wang YL, Cao ZH (2009) Resarch of changing characteristics and control factors of farmland topsoil organic carbon in China. Geogr Res 28(3):601-612 (in Chinese with English abstract)

Yan X, Cai Z, Wang S, Smith P (2011) Direct measurement of soil organic carbon content change in the croplands of China. 
Glob Chang Biol 17:1487-1496. doi:10.1111/j.1365-2486. 2010.02286.x

Yang DW, Li C, Hu HP, Lei ZD, Yang SX, Kusuda T, Koike T, Musiake K (2004) Analysis of water resources variability in the Yellow River of China during the last half century using historical data. Water Resour Res 40. doi: 10.1029/ 2003wr002763

Yang YH, Mohammat A, Feng JM, Zhou R, Fang JY (2007) Storage, patterns and environmental controls of soil organic carbon in China. Biogeochemistry 84:131-141. doi:10.1007/ s10533-007-9109-z

Yang Y, Ji C, Ma W, Wang S, Wang S, Han W, Mohammat A, Robinson D, Smith P (2012) Significant soil acidification across northern China's grasslands during 1980s-2000s. Glob Chang Biol 18:2292-2300. doi:10.1111/j.1365-2486. 2012.02694.x
Yu YY, Guo ZT, Wu HB, Kahmann JA, Oldfield F (2009) Spatial changes in soil organic carbon density and storage of cultivated soils in China from 1980 to 2000. Global Biogeochemical Cycles 23. doi: 10.1029/2008gb003428

Yu J, Wang Y, Li Y, Dong H, Zhou D, Han G, Wu H, Wang G, Mao $\mathrm{P}$, Gao Y (2012) Soil organic carbon storage changes in coastal wetlands of the modern Yellow River Delta from 2000 to 2009. Biogeosciences 9:2325-2331. doi:10.5194/bg-9-2325-2012

Zhang JB, Lin XG, Li H (2011) A new generation of controlling technology for the medium and low yield fields and its potential in large-area balanced grain production increase. Sci Technol Innov Grain Secur 26:375-382

Zhao G, Bryan BA, King D, Luo Z, Wang E, Song X, Yu Q (2013) Impact of agricultural management practices on soil organic carbon: simulation of Australian wheat systems. Glob Chang Biol 19:1585-1597. doi:10.1111/gcb.12145 